\section{UCDNN}

LIBRARY
University of Connecticut OpenCommons@UConn

$11-2015$

\title{
Does a Positive Margin Always Mandate Adjuvant Radiotherapy?
}

Peter C. Albertsen

University of Connecticut School of Medicine and Dentistry

Follow this and additional works at: https://opencommons.uconn.edu/uchcres_articles Part of the Medicine and Health Sciences Commons

\section{Recommended Citation}

Albertsen, Peter C., "Does a Positive Margin Always Mandate Adjuvant Radiotherapy?" (2015). UCHC Articles - Research. 288.

https://opencommons.uconn.edu/uchcres_articles/288 
Despite the strong evidence that ePLND positively affects survival in men with limited lymph node involvement, this procedure is not commonly performed. The reasons for this are multiple and include expertise, stage migration and functional and oncological outcomes, as well as economics and the introduction of laparoscopic and laparoscopic RARP. However, this is no reason not to offer the patient, if possible, an operation which has the highest chance of cure.

\section{Conflicts of Interest}

No conflict of interest.

\section{Martin Spahn}

Department of Urology, University Hospital Bern, Inselspital, Bern, Switzerland

\section{References}

1 Abdollah F, Klett DE, Sood A et al. Predicting pathological outcomes in patients undergoing robot-assisted radical prostatectomy for high- risk prostate cancer: a preoperative nomogram. BJU Int 2014; 116: 703-12

2 Weingartner K, Ramaswamy A, Bittinger A, Gerharz EW, Voge D, Riedmiller $\mathrm{H}$. Anatomical basis for pelvic lymphadenectomy in prostate cancer: results of an autopsy study and implications for the clinic. J Urol 1996; 156: 1969-71

3 Heidenreich A, Varga Z, Von Knobloch R. Extended pelvic lymphadenectomy in patients undergoing radical prostatectomy: high incidence of lymph node metastasis. J Urol 2002; 167: 1681-6

4 Bader P, Burkhard FC, Markwalder R, Studer UE. Is a limited lymph node dissection an adequate staging procedure for prostate cancer? J Urol 2002; 168: 514-8

5 Seiler R, Studer UE, Tschan K, Bader P, Burkhard FC. Removal of limited nodal disease in patients undergoing radical prostatectomy: long-term results confirm a chance for cure. J Urol 2014; 191: $1280-5$

6 Wang EH, Yu JB, Gross CP et al. Variation in pelvic lymph node dissection among patients undergoing radical prostatectomy by hospital characteristics and surgical approach: results from the National Cancer Database. J Urol 2015; 193: 820-5.

\section{Does a positive margin always mandate adjuvant radiotherapy?}

The appropriate treatment for clinically localized prostate cancer continues to generate controversy. For men with low grade disease it is unclear whether surgery or radiation therapy provides a survival advantage over active surveillance, and among men with high grade disease it is unclear how many derive a substantial benefit from either intervention. No trial has yet to compare surgery and radiation with observation, but the recent update of the Scandinavian Prostate Cancer Group 4 study suggests that radical prostatectomy provides a significant survival advantage for younger men with intermediate grade disease [1].

Unfortunately, many men undergoing radical prostatectomy are not cured of their disease. The Scandinavian Prostate Cancer Group 4 study has shown that as many as $26 \%$ of men undergoing surgery developed distant metastases and $18 \%$ died from their disease after a median follow-up of 13 years. For this reason many clinicians recommend additional radiation therapy for those men undergoing surgery who are at high risk of disease recurrence. Three randomized trials now support the use of radiation therapy in this setting. Two have shown lower rates of biochemical progression and one has shown improved distant metastasesfree survival and overall survival [2-4]. These trials compared the use of adjuvant radiation therapy with observation. Some clinicians, however, are reluctant to refer patients for radiation therapy because of concerns about its potential impact on quality of life. This is especially true for those patients who have yet to show any evidence of biochemical recurrence.

In a manuscript published in this month's BJUI, Hsu et al. [5] have turned to a large national prostate cancer registry that has accrued men with newly diagnosed prostate cancer since 1995. They evaluated the long-term outcomes of these men to gain insights into whether a delay in the initiation of radiation therapy compromises survival. Their findings suggest that delaying the initiation of radiation therapy until there is evidence of biochemical recurrence does not seriously compromise long-term outcomes and avoids radiation in some men who are never destined to have disease progression.

The authors are appropriately cautious with their conclusions and clearly recognize the limitations of a non-randomized study. In a registry study it is impossible to control adequately for selection biases. Men receiving adjuvant therapy had no evidence of biochemical recurrence at the time radiation was 
started. This group of men included both men who were destined to have disease progression and men who were destined to maintain an undetectable PSA. This differs from the men receiving salvage radiation therapy. All men receiving salvage radiation had evidence of disease progression and therefore their tumour burden and their long-term prognosis was probably worse when compared with men receiving adjuvant therapy. Despite this selection bias, men initiating salvage radiation when their postoperative PSA level was still $<1.0 \mathrm{ng} / \mathrm{mL}$ had similar long-term outcomes when compared with the men receiving adjuvant radiation. Men with postoperative PSA levels $>1.0 \mathrm{ng} / \mathrm{mL}$ had a much higher risk of aggressive disease and a worse outcome.

Ideally, the question about the timing of postoperative radiation would be subjected to a randomized trial. Until then, the information provided by Hsu et al. provides strong clinical support for a practical approach to the question of who should receive postoperative radiation. Men who are clearly at high risk of disease progression, which includes men with Gleason 8-10 disease and those with extensive margin positive disease and seminal vesicle invasion, should probably receive adjuvant radiation therapy as soon as they have recovered from surgery. For men with Gleason 7 disease or those men who have focal margin-positive disease it may make sense to monitor postoperative PSA levels closely and refer men for postoperative radiation when there is evidence of biochemical progression and before the PSA level reaches $1.0 \mathrm{ng} / \mathrm{mL}$. This approach would spare some men the need for additional treatment and would defer treatment for many years in others. Men who are eventually found to have biochemical recurrence should feel reasonably comfortable that the delay in initiating radiation therapy is unlikely to have caused any significant compromise of their long-term outcome and probably improved their quality of life.
Large case series analyses frequently have selection biases that confound conclusions. In this instance the authors have cautiously interpreted a large community-based registry to gain a valuable insight into the management of localized prostate cancer. Their analysis provides appropriate support for their conclusions.

\section{Conflict of Interest}

The author reports personal fees from Ferring Pharmaceuticals, Tolmar Pharmaceuticals and Blue Cross Blue Shield Technology Assessment Panel, outside the submitted work.

Peter C. Albertsen

University of Connecticut Health Center, Farmington, CT, USA

\section{References}

1 Bill-Axelson A, Holmberg L, Garmo $\mathrm{H}$ et al. Radical prostatectomy or watchful waiting in early prostate cancer. N Engl J Med 2014; 370: 932-42

2 Thompson IM, Tangen CM, Paradelo J et al. Adjuvant radiotherapy for pathological T3N0M0 prostate cancer significantly reduces the risk of metastases and improves survival: long-term followup of a randomized trial. J Urol 2009; 181: 956-62

3 Bolla M, van Poppel H, Collette L et al. Postoperative radiotherapy after radical prostatectomy: a randomized control trial (EORTC trial 22911). Lancet 2005; 366: 572-8

4 Wiegel T, Bottke D, Steiner U et al. Phase III postoperative adjuvant radiotherapy after radical prostatectomy compared with radical prostatectomy alone in $\mathrm{pT} 3$ prostate cancer with postoperative undetectable prostate-specific antigen. ARO 96-02/AUO AP 09/95. J Clin Oncol 2009; 27: 2924-30

5 Hsu D, Paciorek A, Cooperberg M et al. Postoperative radiation therapy for patients at high risk of recurrence after radical prostatectomy: does timing matter? BJU Int 2015; 116: 713-20

\section{Is 42 days the 'magic number' for repeat transurethrall resection of bladder fumour (TURBT)?}

Gökçe et al. [1] have evaluated a group of 242 patients from 10 centres with high-risk non-muscle-invasive bladder cancer (NMIBC) who underwent repeat resection and subsequent follow-up treatment, including induction and maintenance BCG for at least 1 year. They included patients who had repeat transurethral resection (TUR) within 90 days and excluded anyone who was upstaged to T2 or who did not complete 1 year of maintenance BCG. They divided patients into two groups according to time to second TUR, Group A (1442 days) and Group B (43-90 days). The groups were similar in terms of patient age and gender, tumour multifocality, presence of carcinoma in situ (CIS), and stage and grade. The only factors on multivariable analysis that were statistically significant predictors of recurrence were grade, associated CIS, and time to second TUR. Only grade and time to second TUR were significant predictors of progression. 